\title{
Electrocardiographic parameters of left ventricular hypertrophy and prediction of mortality in hemodialysis patients
}

\author{
Matthias C. Braunisch ${ }^{1}(D)$. Peter Gundel ${ }^{1,2} \cdot$ Stanislas Werfel $^{1} \cdot$ Christopher C. Mayer $^{3} \cdot$ Axel Bauer $^{4,5}$. \\ Bernhard Haller $^{6}$ - Roman Günthner ${ }^{1}$. Georg Lorenz ${ }^{1}$ - Susanne Angermann ${ }^{1}$. Julia Matschkal ${ }^{1}$. Carolin Schaller ${ }^{1}$. \\ Christopher Holzmann-Littig ${ }^{1,7}$. Stephan Kemmner ${ }^{1,8}$. Johannes Mann ${ }^{9,10}$. Axel Krieter ${ }^{11}$. Lutz Renders ${ }^{1}$. \\ Siegfried Wassertheurer ${ }^{3}$. Georg Schmidt ${ }^{12}$ - Uwe Heemann ${ }^{1} \cdot$ Marek Malik $^{13,14}$. Christoph Schmaderer ${ }^{1}$
}

Received: 1 March 2021 / Accepted: 9 May 2021 / Published online: 20 May 2021

(c) The Author(s) 2021

\begin{abstract}
Background In hemodialysis patients, left ventricular hypertrophy (LVH) contributes to high cardiovascular mortality. We examined cardiovascular mortality prediction by the recently proposed Peguero-Lo Presti voltage since it identifies more patients with electrocardiographic (ECG) LVH than Cornell or Sokolow-Lyon voltages.

Methods A total of 308 patients on hemodialysis underwent $24 \mathrm{~h} \mathrm{ECG} \mathrm{recordings.} \mathrm{LVH} \mathrm{parameters} \mathrm{were} \mathrm{measured} \mathrm{before}$ and after dialysis. The primary endpoint of cardiovascular mortality was recorded during a median 3-year follow up. Risk prediction was assessed by Cox regression, both unadjusted and adjusted for the Charlson Comorbidity Index and the Cardiovascular Mortality Risk Score.

Results The Peguero-Lo Presti voltage identified with $21 \%$ the most patients with positive LVH criteria. All voltages significantly increased during dialysis. Factors such as ultrafiltration rate, Kt/V, body mass index, sex, and phosphate were the most relevant for these changes. During follow-up, 26 cardiovascular deaths occurred. Post-dialysis Peguero-Lo Presti cut-off as well as the Peguero-Lo Presti and Cornell voltages were independently associated with cardiovascular mortality in unadjusted and adjusted analysis. The Sokolow-Lyon voltage was not significantly associated with mortality. An optimal cut-off for the prediction of cardiovascular mortality was estimated at $1.38 \mathrm{mV}$ for the Peguero-Lo Presti.
\end{abstract}

Matthias C. Braunisch

Matthias.Braunisch@mri.tum.de

Christoph Schmaderer

Christoph.Schmaderer@mri.tum.de

1 Department of Nephrology, School of Medicine, Klinikum Rechts der Isar, Technical University of Munich, Munich, Germany

2 Klinik für Innere Medizin 4, Schwerpunkt Nephrologie und Hypertensiologie, Klinikum Nürnberg, Nuremberg, Germany

3 Center for Health and Bioresources, Biomedical Systems, AIT Austrian Institute of Technology GmbH, Vienna, Austria

4 University Hospital for Internal Medicine III, Medical University Innsbruck, Innsbruck, Austria

5 Department of Cardiology, Munich University Clinic, DZHK (German Centre for Cardiovascular Research), Ludwig-Maximilians University, Munich, Germany

6 Institute of Medical Informatics, Statistics and Epidemiology (IMedIS), School of Medicine, Klinikum Rechts der Isar, Technische Universität München, Munich, Germany
7 TUM Medical Education Center, School of Medicine, Technical University of Munich, Munich, Germany

8 Transplant Center, University Hospital Munich, Ludwig-Maximillians University (LMU), Munich, Germany

9 Department of Nephrology, University of Erlangen-Nürnberg, Erlangen, Germany

10 KfH Kidney Center Munich, Isoldenstraße 15, Munich, Germany

11 Nephrocare München-Ost, Rosenkavalierplatz 5, Munich, Germany

12 School of Medicine, Klinik für Innere Medizin I, Klinikum Rechts der Isar, Technical University of Munich, Munich, Germany

13 National Heart and Lung Institute, Imperial College London, London, UK

14 Department of Internal Medicine and Cardiology, Faculty of Medicine, Masaryk University, Brno, Czech Republic 
Conclusions The post-dialysis Peguero-Lo Presti cut-off as well as the Peguero-Lo Presti and Cornell voltages allowed independent risk prediction of cardiovascular mortality in hemodialysis patients. Measuring the ECG LVH parameters after dialysis might allow a standardized interpretation as dialysis-specific factors influence the voltages.

\section{Graphical abstract}

\section{Electrocardiographic Parameters of Left Ventricular Hypertrophy and Prediction of Mortality in Hemodialysis Patients}

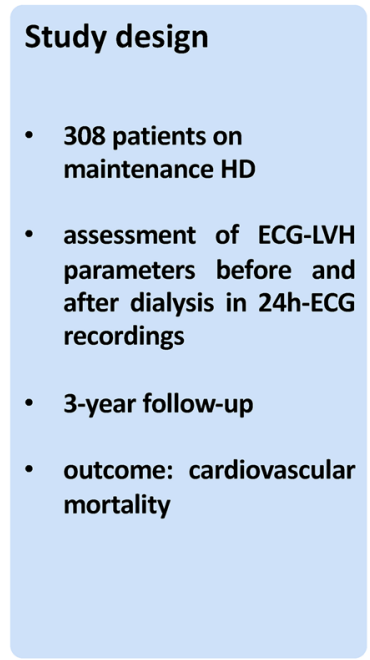

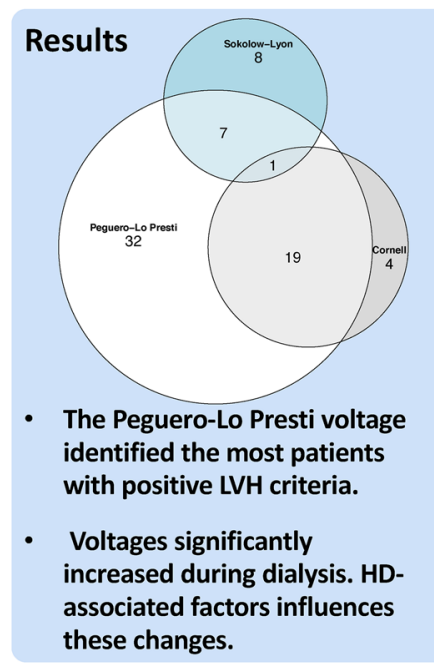
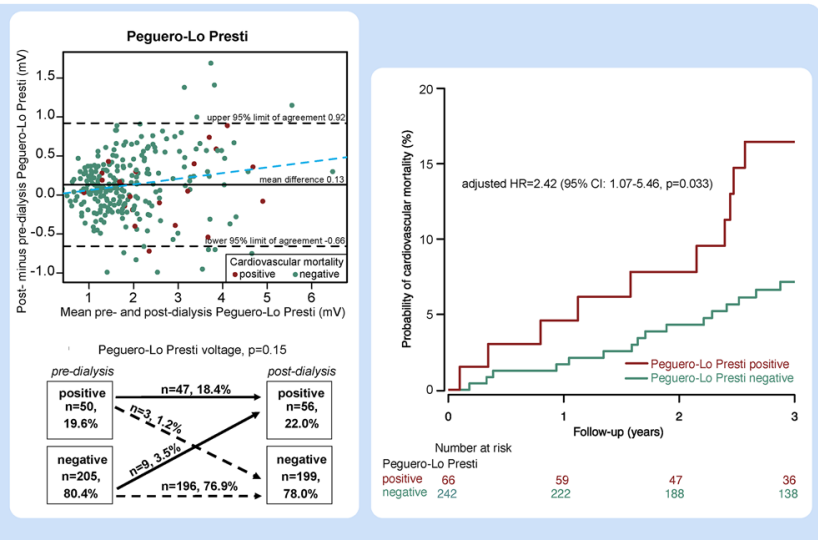

- Post-dialysis Peguero-Lo Presti cut-off as well as the voltages of Peguero-Lo Presti and Cornell were independently associated with cardiovascular mortality in unadjusted and adjusted analysis.

\section{Conclusion}

The ECG yields independent insight into cardiovascular mortality risk associated to LVH in hemodialysis patients. ECG measurement after dialysis might be more suitable for the assessment of ECG LVH because factors such as volume overload are removed by the procedure.

Keywords Left ventricular hypertrophy $\cdot$ Peguero-Lo presti $\cdot$ Cardiovascular mortality $\cdot$ Hemodialysis

\section{Introduction}

End-stage kidney disease patients on hemodialysis have a markedly increased risk of cardiovascular morbidity and mortality [1]. A decline in renal function is associated with left ventricular hypertrophy (LVH) [2]. It was reported that at initiation of renal replacement therapy, $49-74 \%$ of patients show LVH on echocardiography $[3,4]$. This is not surprising since LVH develops as an adaptive response to increased cardiac workload. Multiple factors, including sympathetic activation, increased systemic arterial resistance, elevated blood pressure, reduced large-vessel compliance, and volume overload contribute to increased preand afterload in hemodialysis patients [5, 6]. LVH is also associated with fatal and non-fatal cardiovascular events in hemodialysis patients [7]. Impaired electrophysiology and reduced left ventricular performance, both caused by structural heart disease, increase cardiovascular mortality in dialysis patients. Rapid shifts of electrolytes, volume, and acid-base balance during dialysis have pro-arrhythmogenic potential [8-10].
Despite the high LVH prevalence by echocardiography at dialysis initiation, electrocardiographic (ECG) LVH parameters have low sensitivity compared to echocardiography $[11,12]$. Diffuse myocardial fibrosis in hemodialysis patients might explain lower ECG amplitudes [13, 14]. Nevertheless, the ECG-based LVH indicators also provide mortality risk assessment independent of echocardiographic left ventricular mass data [15]. The recently proposed Peguero-Lo Presti voltage criteria reportedly have higher sensitivity for identifying patients with LVH than the Cornell or Sokolow-Lyon indices [16, 17]. Furthermore, Peguero-Lo Presti voltage criteria were predictive of sudden cardiac death in the general population [17] and have improved the identification of LVH in hemodialysis patients [18].

Keeping all this in mind, we examined the association of ECG-based LVH indices with cardiovascular mortality in hemodialysis patients. Our study aimed at addressing the known limits of standard risk factors for cardiovascular morbidity and mortality in hemodialysis patients $[19,20]$. 


\section{Materials and methods}

\section{Study population}

The study investigated the "rISk strAtification in end-stage Renal disease" (ISAR)-cohort, a multicenter, prospective longitudinal observational cohort study (ClinicalTrials. gov; identifier number: NCT01152892) [21] performed according to STROBE guidelines. The study protocol, conforming to the ethical guidelines of the Helsinki Declaration, was approved by the Medical Ethics Committee of the Klinikum rechts der Isar of the Technical University Munich and of the Bavarian State Board of Physicians. Patients were recruited from 17 hemodialysis centers in the greater Munich area between April 2010 and January 2014. All participants gave written informed consent. Inclusion criteria were age $\geq 18$ years and dialysis vintage $\geq 90$ days [21]. Patients were excluded if pregnant or if suffering from ongoing infection or malignancy with a life expectancy $\leq 24$ months [21]. Out of the 519 patients meeting the inclusion criteria, 390 consented to undergo $24 \mathrm{~h}$ Holter electrocardiogram (ECG) recording. Subjects with low ECG quality $(n=32)$, ventricular paced rhythm $(n=27)$ or complete left or right bundle branch block $(n=23)$ were excluded, leaving 308 participants for the present analysis.

\section{Clinical characteristics}

Baseline demographic and clinical data were obtained from dialysis protocols and medical records. Blood chemistry parameters were obtained prior to a midweek dialysis session. Comorbidities were assessed using an adapted version of the Charlson Comorbidity Index that had previously been validated for mortality prediction in hemodialysis patients [22]. The index assigns numerical weights to the comorbidity conditions of atherosclerotic heart disease (1), heart failure (3), cerebrovascular accident/transient ischemic attack (2), peripheral vascular disease (2), dysrhythmia (2), other cardiac disease (2), chronic obstructive pulmonary disease (2), gastrointestinal bleeding (2), liver disease (2), cancer (2), and diabetes (1). A patient's comorbidity score is the sum of the assigned numerical weights, and ranges between 0 and 21 [22]. Further, to assess cardiovascular mortality risk, the Cardiovascular Mortality Risk Score was calculated [23]. This was previously developed and validated for the prediction of 2-year cardiovascular mortality in hemodialysis patients [23]. It assigns numerical weights to ten domains, namely age $(-5$ to 6 ), body mass index ( -4 to 2 ), presence of a history of cardiovascular disease (2), etiology of chronic kidney disease (0-6), pre-dialysis systolic blood pressure below $120 \mathrm{mmHg}(4)$, net ultrafiltration $(0-3)$, hemoglobin $(-2$ to 2$)$, C-reactive protein (0-5), serum albumin below 3.5 $\mathrm{g} / \mathrm{dL}$ (3), and serum creatinine (0-5). The cardiovascular mortality risk score ranges between -11 and 39 points [23]. Post-dialysis weight was assessed retrospectively and was only available in 148 patients.

\section{Endpoints}

Mortality was assessed using medical records, databases of each dialysis center or by contacting the attending physician or the next of kin. Using this information, the ISAR Endpoint Committee classified the underlying causes of death [21]. Cardiovascular mortality was considered the primary endpoint and all-cause mortality as the secondary endpoint.

\section{Electrocardiography}

In each patient, $24 \mathrm{~h}$ 12-lead ECG data were recorded using the Lifecard CF digital Holter recorder (Delmar Reynolds/ Spacelabs Healthcare, Nuremberg, Germany) starting 5-25 min before a mid-week dialysis session. The first ECG LVH measurement was performed 0-10 min after the start of the recording, representing the pre-dialysis measurement. The second measurement was made 50-70 min after the end of the dialysis session. In cases with artifact-rich ECGs or intermediate signal losses in one or more leads during the pre-specified time ranges, ECG voltages were measured at time points with sufficient ECG quality.

The Peguero-Lo Presti amplitude was calculated using the deepest $\mathrm{S}$ among all 12 leads $+\mathrm{S}_{\mathrm{V} 4}$ [16]. Cornell voltage was calculated as $R_{\mathrm{aVL}}+\mathrm{S}_{\mathrm{V} 3}$ [24]. Sokolow-Lyon voltage was calculated as $\mathrm{SV}_{1}+\mathrm{RV}_{5}$ or $\mathrm{RV}_{6}$ (whichever was greater) [25] (Supplementary Fig. 1). Dichotomy cut-offs were used and set at $\geq 2.3 \mathrm{mV}$ in women, and $\geq 2.8$ in men for Peguero-Lo Presti [16]; $>2.0 \mathrm{mV}$ in women, and $>2.8 \mathrm{mV}$ in men for Cornell [24]; and $\geq 3.5 \mathrm{mV}$ for Sokolow-Lyon [25].

\section{Statistical analysis}

Categorical data are presented as frequencies and percentages. Continuous variables are expressed as mean \pm standard deviation (SD) for normally distributed variables and as median and interquartile range (IQR) for variables with skewed distribution. To test for group differences, $\chi^{2}$ test was used for categorical variables, and the independent samples $t$-test or Mann-Whitney $U$ test was used for continuous variables, as appropriate.

Changes in LVH parameters between pre- and post-dialysis were tested using the Wilcoxon rank test and McNemar test for paired samples, as appropriate. Agreement of pre- and post-dialysis measurements were depicted with 
Bland-Altman plots. Linear regression with backward variable selection according to AIC was used to identify potential predictors of ECG LVH deltas (post-minus pre-dialysis voltage).

Cumulative incidence functions of cardiovascular death probability were computed. Cause-specific hazard for cardiovascular mortality was compared between groups by the log-rank test. Median follow-up was assessed by reverse Kaplan-Meier [26].

Unadjusted and adjusted Cox proportional hazards regression was performed for the endpoints. Adjusted models accounted for the Charlson Comorbidity Index and the Cardiovascular Mortality Risk Score. The predictive performance of pre- vs post-dialysis voltages in the multivariable Cox regression models was compared using Harrell's $\mathrm{C}$-index. $p$-values were calculated by outcome permutations and confidence intervals were calculated by bootstrapping. For the final prediction models, we used the post-dialysis ECG LVH parameters because of significantly higher voltages after dialysis.

The optimal cut-off and the corresponding $p$-value for the Peguero-Lo Presti voltage in the total group was calculated by Maximally Selected Rank Statistics [27, 28].

All tests were conducted two-sided and $p$-values $<0.05$ were considered significant. Statistical analysis was performed using R version 4.0.2 (R Foundation for statistical Computing, Vienna, Austria).

\section{Results}

\section{Patient characteristics}

The study population included 308 patients (106 women; median age was 66.5 years, IQR 53.2-75.5 years) with a median follow-up time of 3.0 years (Fig. 1). The median dialysis vintage was 44.5 (23.8-75.2) months. In 16 (5.2\%) patients a permanent central venous catheter was used as dialysis access (Supplementary Table 1). The prevalence of LVH and hypertension in medical reports was 83 (26.9\%) and 288 (93.5\%), respectively. Measurements of left ventricular ejection fraction were available in $47(15.3 \%)$ patients, in whom the median value was $49 \%$ (44-53\%). A history of myocardial infarction was present in $57(18.5 \%)$ patients.

A pre-dialysis and post-dialysis ECG LVH measurement with sufficient quality was available in $284(92.2 \%)$ and $267(86.7 \%)$ patients, respectively. Patients with a positive post-dialysis Peguero-Lo Presti index $(n=59)$, or in case of missing post-dialysis data, with a positive Peguero-Lo Presti index at another time point $(n=7)$, had lower body mass index, higher ultrafiltration rate in $\mathrm{mL} / \mathrm{kg} / \mathrm{h}$, higher systolic blood pressure, higher phosphate, lower cholesterol, higher prevalence of LVH in medical reports, and were more likely

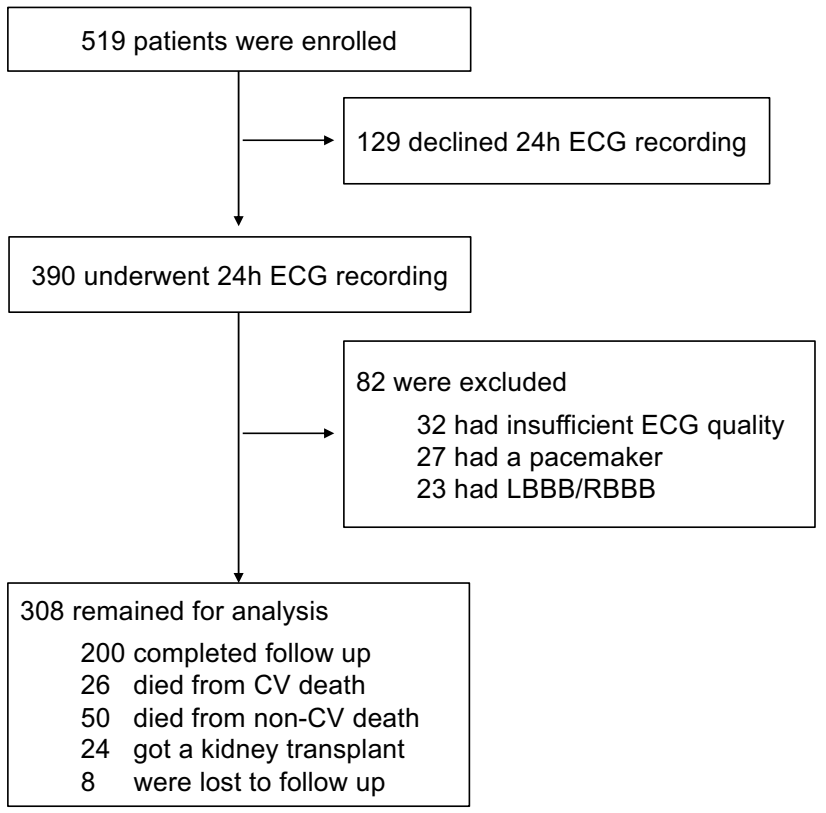

Fig. 1 Flow-chart of participants. Abbreviations: $C V$ cardiovascular; $E C G$ electrocardiogram; $L B B B$ left bundle branch block; $R B B B$ right bundle branch block

to smoke (Table 1). Compared to the excluded patients of the ISAR study cohort, patients in the analyzed population had relatively fewer central venous catheters as dialysis access, fewer comorbidities and lower high-sensitivity C-reactive protein (hsCRP) (Supplementary Table 2). Reasons for cardiovascular and all-cause mortality are presented in Supplementary Table 3.

\section{Changes in ECG LVH voltage during dialysis}

Measurement of ECG LVH parameters was available before and after hemodialysis for 255 (82.8\%) patients. Figure $2 \mathrm{~A}-\mathrm{C}$ depicts the agreement of pre- and post-dialysis voltages. The mean differences were $0.13,0.08$, and 0.12 $\mathrm{mV}$ for the Peguero-Lo Presti, Cornell, and Sokolow-Lyon voltage, respectively. All voltages increased significantly from the pre- to the post-dialysis measurement. Figure 2D-F depicts the changes in voltage between the pre- and postdialysis measurements classified according to established cut-off values. Only the classification for Sokolow-Lyon was significantly more often positive after dialysis (Fig. 2D-F). Figure 3 displays the distribution of positive voltage criteria after dialysis. Of the 148 patients for whom post-dialysis weight measurement was available, 55 (37.2\%), 32 (21.6\%), and $10(6.8 \%)$ were more than $0.5,1$, and $2 \mathrm{~kg}$ above their dry weight, respectively (Supplementary Table 4).

Table 2 lists the most relevant determinants of postminus pre-dialysis voltage deltas of Peguero-Lo Presti, Cornell, and Sokolow-Lyon after backward variable selection. 
Table 1 Baseline characteristics

\begin{tabular}{|c|c|c|c|c|}
\hline & \multirow[t]{2}{*}{ Total $(n=308)$} & \multicolumn{2}{|c|}{ Post-dialysis Peguero-Lo Presti* } & \multirow[t]{2}{*}{$p$} \\
\hline & & Negative $(n=242)$ & Positive $(n=66)$ & \\
\hline Age (years) & $66.5(53.2-75.5)$ & $66.3(53.4-75.4)$ & $68.1(52.4-76.4)$ & 0.67 \\
\hline Sex (female) & $106(34.4 \%)$ & $85(35.1 \%)$ & $21(31.8 \%)$ & 0.66 \\
\hline Body mass index $\left(\mathrm{kg} / \mathrm{m}^{2}\right)$ & $25.1(22.5-28.6)$ & $25.8(22.9-29.0)$ & $23.2(21.1-25.6)$ & $<0.001$ \\
\hline Dialysis vintage (months) & $44.5(23.8-75.2)$ & $41.5(22.0-73.0)$ & $62.0(30.5-78.0)$ & 0.079 \\
\hline Ultrafiltration rate $(\mathrm{mL} / \mathrm{h})$ & $486.2( \pm 254.1)$ & $480.3( \pm 255.1)$ & $507.6( \pm 251.0)$ & 0.44 \\
\hline Ultrafiltration rate $(\mathrm{mL} / \mathrm{kg} / \mathrm{h})$ & $6.6( \pm 3.6)$ & $6.3( \pm 3.3)$ & $7.2( \pm 4.2)$ & 0.004 \\
\hline Net ultrafiltration (L) & $1.7( \pm 1.1)$ & $1.7( \pm 1.1)$ & $1.7( \pm 1.0)$ & 0.84 \\
\hline Hemodialysis access & & & & 0.54 \\
\hline Arteriovenous fistula & $292(94.8 \%)$ & $228(94.2 \%)$ & $64(97.0 \%)$ & \\
\hline Central venous catheter & $16(5.2 \%)$ & $14(5.7 \%)$ & $2(3.0 \%)$ & \\
\hline Post-dialysis Cornell voltage positive & $27(8.8 \%)$ & $4(1.7 \%)$ & $23(34.8 \%)$ & $<0.001$ \\
\hline Post-dialysis Sokolow-Lyon voltage positive & $17(5.5 \%)$ & $9(3.7 \%)$ & $8(12.1 \%)$ & $<0.001$ \\
\hline Heart rate $(\mathrm{bpm})$ & $74.7( \pm 11.8)$ & $75.3( \pm 11.3)$ & $72.6( \pm 13.3)$ & 0.10 \\
\hline Systolic blood pressure (mmHg) & $135.9( \pm 22.4)$ & $134.8( \pm 22.7)$ & $141.0( \pm 22.2)$ & 0.050 \\
\hline Diastolic blood pressure $(\mathrm{mmHg})$ & $75.0(63.8-84.0)$ & $74.5(64.0-84.0)$ & $75.5(63.0-85.8)$ & 0.70 \\
\hline $\mathrm{Kt} / \mathrm{V}$ & $1.44( \pm 0.38)$ & $1.45( \pm 0.39)$ & $1.42( \pm 0.38)$ & 0.59 \\
\hline Blood urea nitrogen $(\mathrm{mg} / \mathrm{dL})$ & $61.2( \pm 16.7)$ & $61.3( \pm 16.9)$ & $60.8( \pm 15.9)$ & 0.82 \\
\hline Phosphate (mmol/L) & $1.69(1.37-2.03)$ & $1.61(1.35-2.01)$ & $1.89(1.45-2.10)$ & 0.040 \\
\hline Total calcium (mmol/L) & $2.28(2.18-2.38)$ & $2.27(2.18-2.39)$ & $2.29(2.15-2.38)$ & 0.97 \\
\hline Calcium $\times$ phosphate $\left(\mathrm{mmol}^{2} / \mathrm{L}^{2}\right)$ & $3.77(3.14-4.62)$ & $3.69(3.08-4.55)$ & $4.17(3.34-4.79)$ & 0.055 \\
\hline Creatinine $(\mathrm{mg} / \mathrm{dL})$ & $8.5( \pm 2.8)$ & $8.5( \pm 2.9)$ & $8.7( \pm 2.7)$ & 0.63 \\
\hline High-sensitivity CRP (mg/dL) & $0.41(0.17-0.92)$ & $0.41(0.16-0.93)$ & $0.37(0.19-0.87)$ & 0.83 \\
\hline Albumin $(\mathrm{g} / \mathrm{dL})$ & $4.00(3.70-4.20)$ & $4.00(3.80-4.30)$ & $3.95(3.70-4.20)$ & 0.46 \\
\hline Parathyroid hormone (pg/mL) & $234.6(123.0-403.0)$ & $227.6(117.0-384.9)$ & $264.0(142.0-488.1)$ & 0.097 \\
\hline Leukocytes (G/L) & $6.90(5.60-8.20)$ & $6.95(5.60-8.28)$ & $6.65(5.23-7.88)$ & 0.37 \\
\hline Total cholesterol (mg/dL) & $174.5(148.8-204.8)$ & $179.0(155.8-206.2)$ & $160.5(131.0-192.2)$ & 0.007 \\
\hline Charlson Comorbidity Index (0 to 21$)$ & $3.0(1.0-5.2)$ & $3.0(1.0-5.0)$ & $3.0(2.0-6.0)$ & 0.13 \\
\hline Cardiovascular mortality risk score ( -11 to 39$)$ & $9.6( \pm 6.6)$ & $9.5( \pm 6.6)$ & $10.4( \pm 6.5)$ & 0.36 \\
\hline Diabetes mellitus & $112(36.4 \%)$ & $87(36.0 \%)$ & $25(37.9 \%)$ & 0.77 \\
\hline History of myocardial infarction & $57(18.5 \%)$ & $40(16.5 \%)$ & $17(25.8 \%)$ & 0.11 \\
\hline Left ventricular hypertrophy & $83(26.9 \%)$ & $55(22.7 \%)$ & $28(42.4 \%)$ & 0.003 \\
\hline Left ventricular ejection fraction $(\%), n=47$ & $49(44-53)$ & $56(37-60)$ & $50(38-60)$ & 0.58 \\
\hline Heart failure & $44(14.3 \%)$ & $30(12.4 \%)$ & $14(21.1 \%)$ & 0.076 \\
\hline Peripheral artery disease & $62(20.1 \%)$ & $49(20.2 \%)$ & $13(19.7 \%)$ & 1.0 \\
\hline Hypertension & $288(93.5 \%)$ & $223(92.1 \%)$ & $65(98.5 \%)$ & 0.088 \\
\hline Coronary heart disease & $95(30.8 \%)$ & $70(28.9 \%)$ & $25(37.9 \%)$ & 0.18 \\
\hline Cerebrovascular disease & $42(13.6 \%)$ & $37(15.3 \%)$ & $5(7.6 \%)$ & 0.15 \\
\hline Smoking (ever) & $73(23.7 \%)$ & $50(20.7 \%)$ & $23(34.8 \%)$ & 0.022 \\
\hline
\end{tabular}

Results are presented as mean $( \pm \mathrm{SD})$ and median (interquartile range) for normally and non-normally distributed data, respectively; categorical data as total number (percentage). $p$-values present the results of group-wise comparisons of patients with positive and negative Peguero-Lo Presti Index

*Including $n=41$ replaced missing post-dialysis voltages

\section{Association of ECG LVH parameters and mortality}

Altogether, 26 and 50 patients died due to cardiovascular and non-cardiovascular causes of death, respectively. Patients were censored at the last day of dialysis in case of kidney transplantation $(n=24)$ or if lost to follow-up $(n=8)$.

In both unadjusted and adjusted analyses, the PegueroLo Presti and Cornell voltages were significantly associated with cardiovascular mortality (Table 3 ). A voltage 

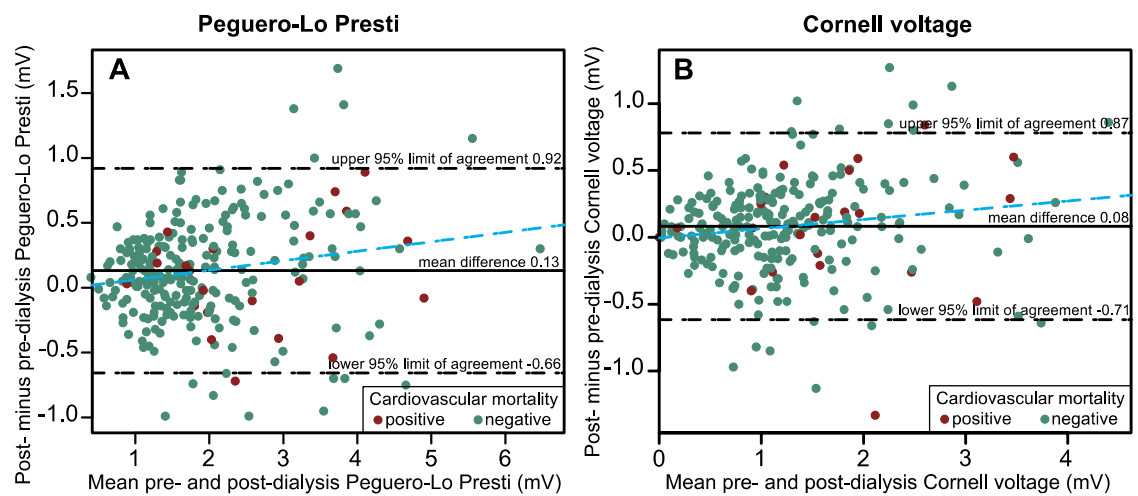

D Peguero-Lo Presti voltage, $\mathrm{p}=0.15$
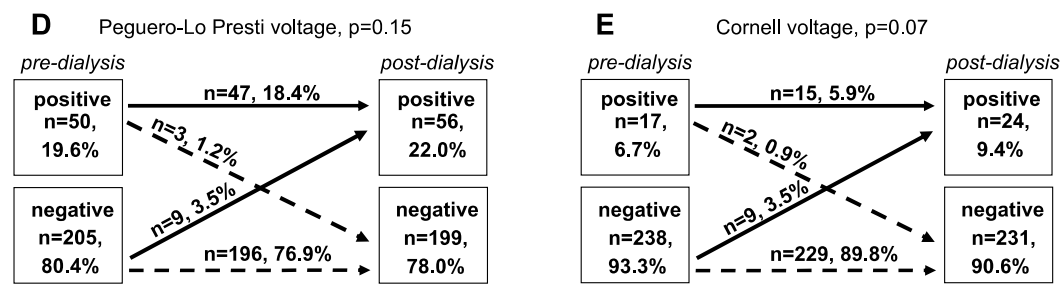

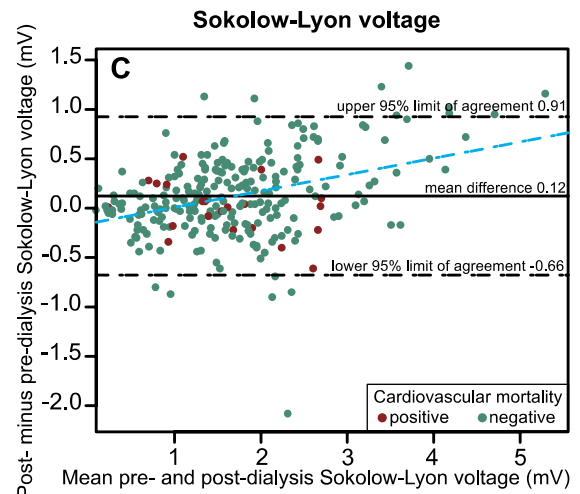

F Sokolow-Lyon voltage, $p=0.045$

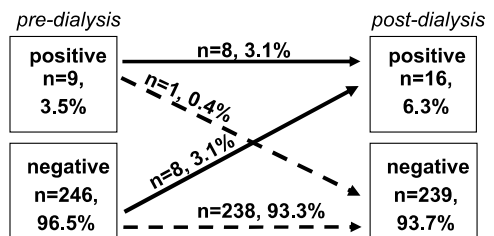

Fig. 2 Changes in pre- to post-dialysis voltages. A-C show BlandAltman plots for the agreement of pre- and post-dialysis voltages. The black line depicts the mean difference between the two measurements, the dotted lines depict the limits of agreement (mean delta

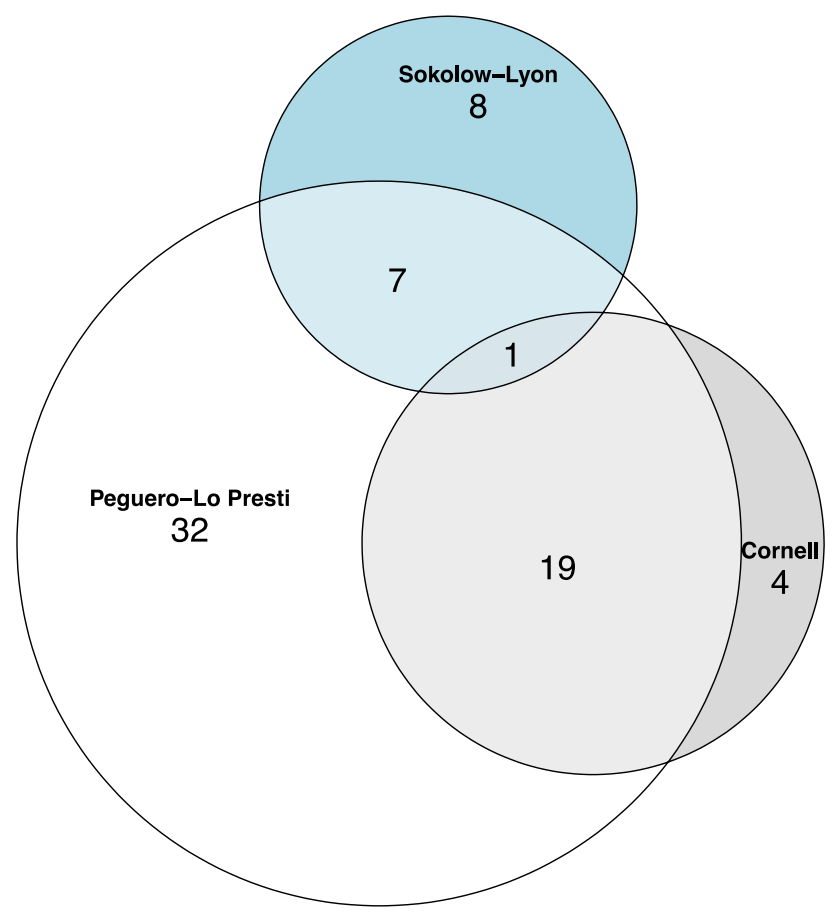

Fig. 3 Area-proportional Euler diagrams of positive ECG LVH voltage criteria measured after dialysis. Peguero-Lo Presti $(n=59): \geq 2.3$ $\mathrm{mV}$ (women), $\geq 2.8$ (men); Cornell $(n=24):>2.0 \mathrm{mV}$ (women), $>2.8$ $\mathrm{mV}$ (men); Sokolow-Lyon $(n=16): \geq 3.5 \mathrm{mV}$
- $1.96 \times$ standard deviation to mean delta $+1.96 \times$ standard deviation). The blue dotted line describes the regression line. D-F show the changes in voltage cut-offs from pre- to post-dialysis which were compared using the McNemar test

increase of $1 \mathrm{mV}$ was associated with an increased cardiovascular mortality risk of $46 \%$ and $62 \%$ for the PegueroLo Presti and Cornell voltage, respectively. Only classification according to the Peguero-Lo Presti cut-off was significantly associated with cardiovascular mortality in unadjusted and adjusted analyses. The three-year cardiovascular mortality rate was $7.2 \%$ and $16.5 \%$ in the Peguero-Lo Presti negative and positive group, respectively (Fig. 4). The Sokolow-Lyon index had no significant predictive cardiovascular association in both unadjusted and adjusted models. No associations of the ECG LVH parameters to all-cause mortality were present (Table 4). $\mathrm{C}$-index comparison of multivariable Cox regression models showed no significant superiority of pre- vs post-dialysis Peguero-Lo Presti voltage $(0.83,95 \%$ CI: $0.76-0.90$ vs 0.82, 95\% CI: $0.75-0.89 ; p=0.46)$. Similarly, there was no significant difference between the concordances obtained with pre- and post-dialysis Cornell voltages $(0.82,95 \% \mathrm{CI}$ : $0.74-0.90$ vs $0.81,95 \% \mathrm{CI}: 0.73-0.89 ; p=0.32)$.

Maximally selected rank statistics revealed an optimal cut-off for the Peguero-Lo Presti voltage at $1.38 \mathrm{mV}$ for the prediction of cardiovascular mortality with a $p$-value of 0.044. No such significant cut-off was found for the Cornell or Sokolow-Lyon voltages. 
Table 2 Final models of backward linear regressions to identify predictors of post- minus pre-dialysis voltages

\begin{tabular}{|c|c|c|c|c|c|c|}
\hline \multirow[t]{2}{*}{ Predictor } & \multicolumn{2}{|l|}{ Delta Peguero-Lo Presti } & \multicolumn{2}{|l|}{ Delta Cornell voltage } & \multicolumn{2}{|c|}{ Delta Sokolow-Lyon voltage } \\
\hline & $b(95 \% \mathrm{CI})$ & $p$ & $b(95 \% \mathrm{CI})$ & $p$ & $b(95 \% \mathrm{CI})$ & $p$ \\
\hline (Intercept) & $-0.83(-1.26$ to -0.39$)$ & $<0.001$ & $0.05(-0.16$ to 0.26$)$ & 0.64 & $-0.02(-0.43$ to 0.39$)$ & 0.92 \\
\hline Female sex & $-0.15(-0.26$ to -0.05$)$ & 0.003 & $-0.08(-0.17$ to 0.01$)$ & 0.078 & - & - \\
\hline Ultrafiltration rate $(\mathrm{mL} / \mathrm{kg} / \mathrm{h})$ & $0.03(0.02-0.04)$ & $<0.001$ & $0.16(-0.00$ to 0.03$)$ & 0.009 & - & - \\
\hline Present central venous catheter & $-0.18(-0.39$ to 0.03$)$ & 0.090 & $-0.22(-0.41$ to -0.03$)$ & 0.024 & & \\
\hline Systolic blood pressure (10 mmHg) & $0.02(-0.01$ to 0.04$)$ & 0.14 & - & - & - & - \\
\hline $\mathrm{Kt} / \mathrm{V}$ & $0.16(0.03$ to 0.28$)$ & 0.016 & - & - & $0.13(-0.00$ to 0.26$)$ & 0.057 \\
\hline Phosphate $(\mathrm{mmol} / \mathrm{L})$ & $0.12(0.04$ to 0.20$)$ & 0.004 & $0.06(-0.02$ to 0.13$)$ & 0.14 & - & - \\
\hline Total cholesterol $(50 \mathrm{mg} / \mathrm{dL})$ & $0.05(-0.01$ to 0.10$)$ & 0.084 & - & - & $0.05(-0.00$ to 0.10$)$ & 0.071 \\
\hline Leukocytes (G/L) & & & $-0.02(-0.05$ to 0.00$)$ & 0.030 & - & - \\
\hline Present peripheral artery disease & & & $0.08(-0.02$ to 0.19$)$ & 0.13 & & \\
\hline Current smoker & & & $0.08(-0.02$ to 0.19$)$ & 0.12 & - & - \\
\hline Body mass index $\left(10 \mathrm{~kg} / \mathrm{m}^{2}\right)$ & & & & & $-0.09(-0.18$ to 0.01$)$ & 0.064 \\
\hline Present heart failure & & & & & $0.12(-0.03$ to 0.26$)$ & $\begin{array}{l}0.11 \\
0.11\end{array}$ \\
\hline Present cerebrovascular disease & & & & & $-0.10(-0.25$ to 0.04$)$ & 0.16 \\
\hline
\end{tabular}

$R^{2}$ (Delta Peguero-Lo Presti) $=0.17 ; R^{2}$ (Delta Cornell voltage $)=0.09 ; R^{2}$ (Delta Sokolow-Lyon voltage $)=0.07 . b$ regression coefficient; $C I$ confidence interval. Included predictors: age, sex, body mass index, dialysis vintage, ultrafiltration in $\mathrm{mL} / \mathrm{kg} / \mathrm{h}$, dialysis access, heart rate, systolic blood pressure, Kt/V, blood urea nitrogen, phosphate, total calcium, creatinine, high-sensitivity CRP, parathyroid hormone, leukocytes, total cholesterol, diabetes mellitus, history of myocardial infarction, left ventricular hypertrophy, heart failure, peripheral artery disease, hypertension, coronary heart disease, cerebrovascular disease, smoking. Replacement of missing values: 15 high-sensitivity C-reactive protein (hsCRP) replaced by non-hsCRP values; three total calcium, three parathyroid hormone and 34 total cholesterol values replaced by dialysis center-specific means

Table 3 Association of risk variables with cardiovascular mortality in unadjusted and adjusted analysis

\begin{tabular}{|c|c|c|c|c|c|}
\hline \multirow[t]{2}{*}{ Variable } & \multirow[t]{2}{*}{ Unit } & \multicolumn{2}{|l|}{ Unadjusted } & \multicolumn{2}{|l|}{ Adjusted } \\
\hline & & HR $(95 \% \mathrm{CI})$ & $p$ & HR $(95 \% \mathrm{CI})$ & $p$ \\
\hline Peguero-Lo Presti (categorial) & Present & $2.43(1.11-5.37)$ & 0.027 & $2.22(1.01-4.91)$ & 0.048 \\
\hline Peguero-Lo Presti & $1 \mathrm{mV}$ & $1.47(1.12-1.95)$ & 0.006 & $1.46(1.10-1.93)$ & 0.009 \\
\hline Cornell voltage (categorial) & Present & $2.52(0.95-6.67)$ & 0.064 & $2.49(0.94-6.64)$ & 0.067 \\
\hline Cornell voltage & $1 \mathrm{mV}$ & $1.64(1.09-2.50)$ & 0.019 & $1.62(1.06-2.47)$ & 0.025 \\
\hline Sokolow-Lyon voltage (categorial) & Present & NA & NA & & \\
\hline Sokolow-Lyon voltage & $1 \mathrm{mV}$ & $0.94(0.62-1.43)$ & 0.78 & $1.22(0.82-1.82)$ & 0.32 \\
\hline Charlson Comorbidity Index & 1 point & $1.28(1.15-1.42)$ & $<0.001$ & - & - \\
\hline Cardiovascular mortality risk score & 1 point & $1.12(1.05-1.19)$ & $<0.001$ & - & - \\
\hline
\end{tabular}

Each row represents one unadjusted and one adjusted model. Adjusted model for Charlson Comorbidity Index and Cardiovascular Mortality Risk Score. Abbreviations: CI confidence interval; NA not applicable since there were no cardiovascular mortality events in the positive group

\section{Discussion}

Our study in hemodialysis patients showed that the postdialysis Peguero-Lo Presti cut-off as well as the PegueroLo Presti and Cornell voltages provide prognostic information on cardiovascular mortality risk even after adjusting for strong risk factors. Moreover, we found higher voltages after dialysis and several dialysis-associated factors influencing these voltages.
The post-dialysis Peguero-Lo Presti identified higher numbers of patients with positive LVH criteria. It almost completely overlapped with patients that had a positive Cornell voltage and by half with patients who had a positive Sokolow-Lyon voltage. However, post-dialysis Peguero-Lo Presti criteria were fulfilled in $21 \%$ of our patients, which still represents a low prevalence because it is known that up to $74 \%$ of dialysis patients show LVH on echocardiography at dialysis initiation [3]. Nevertheless, the observed prevalence of positive LVH criteria agrees 

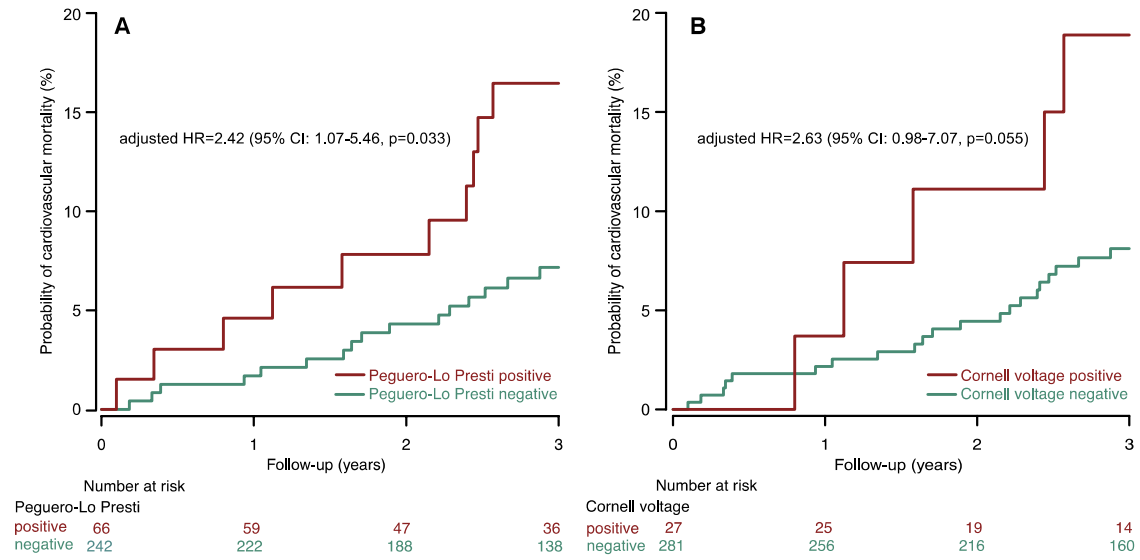

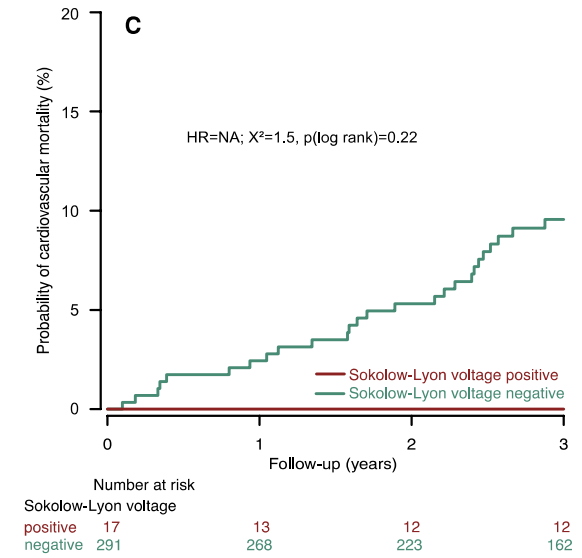

Fig. 4 Cumulative cardiovascular mortality curves stratified by postdialysis A Peguero-Lo Presti, B Cornell, and C Sokolow-Lyon cutoffs. Hazard ratio after adjustment for the Charlson Comorbidity
Index and the Cardiovascular Mortality Risk Score. Abbreviations: $C I$ confidence interval; $H R$ hazard ratio; $N A$ not applicable since there were no mortality events in the positive group
Table 4 Association of left ventricular hypertrophy electrocardiogram parameters with all-cause mortality in unadjusted and adjusted analysis

\begin{tabular}{|c|c|c|c|c|c|}
\hline \multirow[t]{2}{*}{ Variable } & \multirow[t]{2}{*}{ Unit } & \multicolumn{2}{|l|}{ Unadjusted } & \multicolumn{2}{|l|}{ Adjusted } \\
\hline & & HR $(95 \% \mathrm{CI})$ & $p$ & $\overline{\mathrm{HR}}(95 \% \mathrm{CI})$ & $p$ \\
\hline Peguero-Lo Presti (categorial) & Present & $1.29(0.77-2.17)$ & 0.33 & $1.21(0.72-2.04)$ & 0.47 \\
\hline Peguero-Lo Presti & $1 \mathrm{mV}$ & $1.14(0.93-1.39)$ & 0.21 & $1.13(0.93-1.39)$ & 0.22 \\
\hline Cornell voltage (categorial) & Present & $1.61(0.83-3.13)$ & 0.16 & $1.64(0.84-3.20)$ & 0.15 \\
\hline Cornell voltage & $1 \mathrm{mV}$ & $1.18(0.90-1.54)$ & 0.23 & $1.16(0.89-1.51)$ & 0.28 \\
\hline Sokolow-Lyon voltage (categorial) & Present & NA & NA & & \\
\hline Sokolow-Lyon voltage & $1 \mathrm{mV}$ & $0.80(0.62-1.04)$ & 0.10 & $1.10(0.85-1.41)$ & 0.48 \\
\hline Charlson Comorbidity Index & 1 point & $1.28(1.21-1.36)$ & $<0.001$ & - & - \\
\hline Cardiovascular Mortality Risk Score & 1 point & $1.14(1.10-1.18)$ & $<0.001$ & - & - \\
\hline
\end{tabular}

Each row represents one unadjusted and one adjusted model. Adjusted model for Charlson Comorbidity Index and Cardiovascular Mortality Risk Score. Abbreviations: CI confidence interval; NA not applicable since there were no mortality events in the positive group with other studies in dialysis as well as in non-dialysis patients $[17,29]$ and documents their known low sensitivity $[11,30]$ although echocardiography is known to overestimate left ventricular mass in comparison to magnetic resonance imaging in dialysis patients [31].

All voltage measurements increased over the course of dialysis. Changes in ECG amplitude have been suggested to reflect changes in impedance, most likely due to volume overload, rather than actual electrophysiological alterations [10,32]. Augmented ECG amplitudes have been previously reported at the end of a hemodialysis session and ECG interpretation in the context of the recording time with regard to dialysis treatment has been emphasized $[12,32]$. Regression analysis suggests that dialysis-associated factors such as ultrafiltration, $\mathrm{Kt} / \mathrm{V}$ and phosphate are determinants of voltage changes. Other factors such as the presence of a central venous catheter as dialysis access, lower body mass index, and female sex might influence the voltage parameters more generally and independently of the dialysis procedures [30, 33, 34].

The risk predictive performance of voltage measurements was not different when using the pre- or post-dialysis ECGs. Post-dialysis measurements might however be more suitable for standardized interpretation because the influence of volume overload is removed by the procedure. Due to higher voltages after dialysis, we chose these measurements for survival analysis. In addition to identifying a greater number of positive patients (in agreement with the echocardiographic incidence data [16]), we found that the classification according to the Peguero-Lo Presti prospective cut-off was associated with cardiovascular mortality in the unadjusted and adjusted models, while the prospective classification with regard to cut-offs of the other criteria were not. Furthermore, we identified associations of the PegueroLo Presti and Cornell voltages with cardiovascular mortality after adjustment for the Charlson Comorbidity Index and the 
Cardiovascular Mortality Risk Score. Both adjustment variables are characterized by strong predictive power in dialysis patients [22, 23]. Besides age, cardiovascular comorbidity, and the primary renal disease, the cardiovascular mortality risk score also includes laboratory parameters. Importantly, it also includes dialysis-specific risk factors such as low systolic blood pressure or low serum albumin, since traditional risk factors applicable to the general population lack predictive mortality risk value in dialysis patients [19, 20]. The Peguero-Lo Presti and Cornell voltage therefore provide valuable independent information for risk prediction in these patients. Hence, in agreement with previous reports, the Peguero-Lo Presti voltage might be preferable for risk prediction in this population [11, 29, 31]. As expected, and comparable to previous studies, not only did the SokolowLyon voltage identify fewer positive patients, but it was also not predictive of mortality $[29,35]$.

When searching for an optimal cut-off for the Peguero-Lo Presti voltage in our population, we found a relatively low cut-off of $1.38 \mathrm{mV}$ for optimal risk stratification. This is in contrast to a previous study in patients without end-stage kidney disease that proposed a higher cut-off of $4.0 \mathrm{mV}$ for the prediction of cardiovascular mortality [36]. Lower ECG amplitudes in dialysis patients are caused by an increased prevalence of volume overload leading to increased impedance, but also by diffuse myocardial fibrosis [13, 37]. Therefore, evaluation of a specific cut-off for hemodialysis patients might be reasonable.

Monitoring ECG LVH voltages over time in hemodialysis patients could help to identify those with increased voltages rather than being a strict indicator of pathological LVH. Other methods such as echocardiography or magnetic resonance imaging are more sensitive for this purpose $[11,29,31]$. Longitudinal imaging data in dialysis patients suggest that changes in left ventricular mass are associated with cardiovascular events and mortality [7, 38]. However, the ECG and the echocardiographic finding of LVH may provide distinct risk information reflecting electrical versus anatomical remodeling [39]. It has been observed that dialysis patients with persistently positive ECG LVH had a significantly lower survival rate compared to patients who developed de novo LVH, those without LVH or those with LVH regression [29]. Therefore, it remains to be determined whether repetitive measurements of ECG LVH voltages have comparable prognostic validity. Routine twice-yearly ECG measurement after hemodialysis might be reasonable and feasible in hemodialysis patients as it provides a readily available, non-invasive and inexpensive tool.

Several studies have shown that LVH determined by echocardiography might be modified in dialysis patients [40]. Available data to treat LVH focus on factors associated with LVH development in hemodialysis patients such as management of anemia, hypertension including inhibition of the renin angiotensin aldosterone system, hypervolemia and disorders of the mineral metabolism [14, 41-44] as well as dialysis frequency [45]. In addition, reduced left ventricular mass has been reported after kidney transplantation [46]. However, in a meta-analysis with over 6500 participants with any stage of chronic kidney disease, including one third of patients on dialysis, and excluding recipients of a kidney transplantation, no clear association between interventioninduced left ventricular mass change and mortality was observed [47].

Finally, limitations of the present study have to be considered. The high frailty in our cohort limited the number of available ECGs. Myocardial imaging and assessment of weight changes during dialysis were not part of the study protocol. Due to the low number of cardiovascular events, adjusted Cox regression analysis was limited. We tried to account for this limitation by using two specific, well validated and strongly predictive risk scores for adjusted analyses. We have proposed a different cut-off for the Peguero-Lo Presti index for risk stratification. However, sex specific separation could not be reasonably calculated due to the lower number of female patients with events. Furthermore, this retrospectively determined cut-off requires further validation in other dialysis cohorts.

\section{Conclusion}

In conclusion, the post-dialysis Peguero-Lo Presti cut-off, which identified a higher number of positive patients, as well as the Peguero-Lo Presti and Cornell voltage allow an independent risk prediction of cardiovascular mortality in hemodialysis patients. We found dialysis-associated parameters to disguise voltage amplitudes. Measurement after dialysis where higher voltages are present might allow standardized interpretation.

Supplementary Information The online version contains supplementary material available at https://doi.org/10.1007/s40620-021-01068-0.

Acknowledgements We would like to thank all patients for their participation in the study.

Author contribution This article was conceptualized by Matthias Christoph Braunisch and Christoph Schmaderer. Matthias Christoph Braunisch and Peter Gundel wrote the first draft of the manuscript. Matthias Christoph Braunisch, Peter Gundel, Stanislas Werfel, and Bernhard Haller performed the statistical analysis. Matthias Christoph Braunisch, Peter Gundel, Roman Günthner, Georg Lorenz, Susanne Angermann, Julia Matschkal, Carolin Schaller, Christopher Holzmann-Littig, Stephan Kemmner, Johannes Mann, and Axel Krieter contributed to the data acquisition. Raw ECG data processing was performed by Christopher C. Mayer and Siegfried Wassertheurer. Christoph Schmaderer, Lutz Renders, Georg Schmidt, Uwe Heemann, and Marek Malik contributed to the supervision. All co-authors were involved with data interpretation, revising the work and provided 
important intellectual content. All authors have seen and approved the final manuscript.

Funding Open Access funding enabled and organized by Projekt DEAL. There was no funding for this study.

Availability of data and material Matthias Christoph Braunisch, Peter Gundel and Christoph Schmaderer had full access to all of the data in the study and take responsibility for the integrity of the data and the accuracy of the data analysis.

Code availability Not applicable.

\section{Declarations}

Conflicts of interest The authors declare no conflicts of interest. Matthias Christoph Braunisch reports received personal fees from Vifor Pharma unrelated to the project.

Ethics approval The study protocol adhered to the Helsinki Declaration. It was approved by the Medical Ethics Committee of the Klinikum rechts der Isar of the Technical University Munich and of the Bavarian State Board of Physicians. All involved subjects provided an informed consent to participate and for data publication.

Open Access This article is licensed under a Creative Commons Attribution 4.0 International License, which permits use, sharing, adaptation, distribution and reproduction in any medium or format, as long as you give appropriate credit to the original author(s) and the source, provide a link to the Creative Commons licence, and indicate if changes were made. The images or other third party material in this article are included in the article's Creative Commons licence, unless indicated otherwise in a credit line to the material. If material is not included in the article's Creative Commons licence and your intended use is not permitted by statutory regulation or exceeds the permitted use, you will need to obtain permission directly from the copyright holder. To view a copy of this licence, visit http://creativecommons.org/licenses/by/4.0/.

\section{References}

1. Foley RN, Parfrey PS, Sarnak MJ (1998) Clinical epidemiology of cardiovascular disease in chronic renal disease. Am J Kidney Dis 32(5 Suppl 3):S112-119. https://doi.org/10.1053/ajkd.1998. v32.pm9820470

2. Paoletti E, Bellino D, Cassottana P, Rolla D, Cannella G (2005) Left ventricular hypertrophy in nondiabetic predialysis CKD. Am J Kidney Dis 46(2):320-327. https://doi.org/10.1053/j.ajkd.2005. 04.031

3. Foley RN, Parfrey PS, Harnett JD, Kent GM, Martin CJ, Murray DC, Barre PE (1995) Clinical and echocardiographic disease in patients starting end-stage renal disease therapy. Kidney Int 47(1):186-192. https://doi.org/10.1038/ki.1995.22

4. Hickson LJ, Negrotto SM, Onuigbo M, Scott CG, Rule AD, Norby SM, Albright RC, Casey ET, Dillon JJ, Pellikka PA, Pislaru SV, Best PJM, Villarraga HR, Lin G, Williams AW, Nkomo VT (2016) Echocardiography criteria for structural heart disease in patients with end-stage renal disease initiating hemodialysis. J Am Coll Cardiol 67(10):1173-1182. https://doi.org/10.1016/j.jacc.2015. 12.052

5. Ozkahya M, Ok E, Cirit M, Aydin S, Akçiçek F, Başçi A, Dorhout Mees EJ (1998) Regression of left ventricular hypertrophy in haemodialysis patients by ultrafiltration and reduced salt intake without antihypertensive drugs. Nephrol Dial Transplant 13(6):1489-1493. https://doi.org/10.1093/ndt/13.6.1489

6. Gross ML, Ritz E (2008) Hypertrophy and fibrosis in the cardiomyopathy of uremia-beyond coronary heart disease. Semin Dial 21(4):308-318. https://doi.org/10.1111/j.1525-139X.2008. 00454.x

7. Zoccali C, Benedetto FA, Mallamaci F, Tripepi G, Giacone G, Stancanelli B, Cataliotti A, Malatino LS (2004) Left ventricular mass monitoring in the follow-up of dialysis patients: prognostic value of left ventricular hypertrophy progression. Kidney Int 65(4):1492-1498. https://doi.org/10.1111/j.1523-1755.2004. 00530.x

8. Roy-Chaudhury P, Tumlin JA, Koplan BA, Costea AI, Kher V, Williamson D, Pokhariyal S, Charytan DM (2018) Primary outcomes of the monitoring in dialysis study indicate that clinically significant arrhythmias are common in hemodialysis patients and related to dialytic cycle. Kidney Int 93(4):941-951. https:// doi.org/10.1016/j.kint.2017.11.019

9. Bleyer AJ, Hartman J, Brannon PC, Reeves-Daniel A, Satko SG, Russell G (2006) Characteristics of sudden death in hemodialysis patients. Kidney Int 69(12):2268-2273. https://doi.org/10. 1038/sj.ki.5000446

10. Poulikakos D, Malik M (2016) Challenges of ECG monitoring and ECG interpretation in dialysis units. J Electrocardiol. https://doi.org/10.1016/j.jelectrocard.2016.07.019

11. Bacharova L, Schocken D, Estes EH, Strauss D (2014) The role of ECG in the diagnosis of left ventricular hypertrophy. Curr Cardiol Rev 10(3):257-261

12. Skampardoni S, Poulikakos D, Malik M, Green D, Kalra PA (2018) The potential of electrocardiography for cardiac risk prediction in chronic and end-stage kidney disease. Nephrol Dial Transplant. https://doi.org/10.1093/ndt/gfy255

13. Maanja M, Wieslander B, Schlegel TT, Bacharova L, Abu Daya H, Fridman Y, Wong TC, Schelbert EB, Ugander M (2017) Diffuse myocardial fibrosis reduces electrocardiographic voltage measures of left ventricular hypertrophy independent of left ventricular mass. J Am Heart Assoc 6(1). https://doi.org/10. 1161/jaha.116.003795

14. Glassock RJ, Pecoits-Filho R, Barberato SH (2009) Left ventricular mass in chronic kidney disease and ESRD. Clin J Am Soc Nephrol 4(Suppl 1):S79-S91. https://doi.org/10.2215/cjn. 04860709

15. Sundström J, Lind L, Arnlöv J, Zethelius B, Andrén B, Lithell HO (2001) Echocardiographic and electrocardiographic diagnoses of left ventricular hypertrophy predict mortality independently of each other in a population of elderly men. Circulation 103(19):2346-2351. https://doi.org/10.1161/01.cir.103.19.2346

16. Peguero JG, Lo Presti S, Perez J, Issa O, Brenes JC, Tolentino A (2017) Electrocardiographic criteria for the diagnosis of left ventricular hypertrophy. J Am Coll Cardiol 69(13):1694-1703. https://doi.org/10.1016/j.jacc.2017.01.037

17. Porthan K, Kentta T, Niiranen TJ, Nieminen MS, Oikarinen L, Viitasalo M, Hernesniemi J, Jula AM, Salomaa V, Huikuri HV, Albert CM, Tikkanen JT (2019) ECG left ventricular hypertrophy as a risk predictor of sudden cardiac death. Int J Cardiol 276:125-129. https://doi.org/10.1016/j.ijcard.2018.09.104

18. Rodrigues TS, Azraai M, Crosthwaite A, Patel S, Farouque O, Ramchand J, Lim R, Roberts M, Ierino F, Burrell L (2019) The Peguero-Lo Presti criteria improve the sensitivity of the electrocardiogram to diagnose left ventricular hypertrophy in patients with end-stage kidney disease. Heart Lung Circ 28. https://doi. org/10.1016/j.hlc.2019.06.439

19. Stenvinkel P, Carrero JJ, Axelsson J, Lindholm B, Heimburger O, Massy Z (2008) Emerging biomarkers for evaluating cardiovascular risk in the chronic kidney disease patient: how do 
new pieces fit into the uremic puzzle? Clin J Am Soc Nephrol 3(2):505-521. https://doi.org/10.2215/cjn.03670807

20. Ortiz A, Massy ZA, Fliser D, Lindholm B, Wiecek A, MartinezCastelao A, Covic A, Goldsmith D, Suleymanlar G, London GM, Zoccali C (2011) Clinical usefulness of novel prognostic biomarkers in patients on hemodialysis. Nat Rev Nephrol 8(3):141-150. https://doi.org/10.1038/nrneph.2011.170

21. Schmaderer C, Tholen S, Hasenau AL, Hauser C, Suttmann Y, Wassertheurer S, Mayer CC, Bauer A, Rizas KD, Kemmner S, Kotliar K, Haller B, Mann J, Renders L, Heemann U, Baumann M (2016) Rationale and study design of the prospective, longitudinal, observational cohort study "rISk strAtification in end-stage renal disease" (ISAR) study. BMC Nephrol 17(1):161. https://doi.org/10.1186/s12882-016-0374-8

22. Liu J, Huang Z, Gilbertson DT, Foley RN, Collins AJ (2010) An improved comorbidity index for outcome analyses among dialysis patients. Kidney Int 77(2):141-151. https://doi.org/10.1038/ ki. 2009.413

23. Anker SD, Gillespie IA, Eckardt KU, Kronenberg F, Richards S, Drueke TB, Stenvinkel P, Pisoni RL, Robinson BM, Marcelli D, Froissart M, Floege J (2016) Development and validation of cardiovascular risk scores for haemodialysis patients. Int J Cardiol 216:68-77. https://doi.org/10.1016/j.ijcard.2016.04.151

24. Casale PN, Devereux RB, Alonso DR, Campo E, Kligfield P (1987) Improved sex-specific criteria of left ventricular hypertrophy for clinical and computer interpretation of electrocardiograms: validation with autopsy findings. Circulation 75(3):565572. https://doi.org/10.1161/01.cir.75.3.565

25. Sokolow M, Lyon TP (1949) The ventricular complex in left ventricular hypertrophy as obtained by unipolar precordial and limb leads. Am Heart J 37(2):161-186. https://doi.org/10.1016/00028703(49)90562-1

26. Schemper M, Smith TL (1996) A note on quantifying follow-up in studies of failure time. Control Clin Trials 17(4):343-346

27. Hothorn T, Lausen B (2003) On the exact distribution of maximally selected rank statistics. Comput Stat Data Anal 43(2):121137. https://doi.org/10.1016/s0167-9473(02)00225-6

28. Lausen B, Hothorn T, Bretz F, Schumacher M (2004) Assessment of optimal selected prognostic factors. Biom J 46(3):364-374. https://doi.org/10.1002/bimj.200310030

29. Covic AC, Buimistriuc LD, Green D, Stefan A, Badarau S, Kalra PA (2013) The prognostic value of electrocardiographic estimation of left ventricular hypertrophy in dialysis patients. Ann Noninvasive Electrocardiol 18(2):188-198. https://doi.org/10.1111/ anec. 12007

30. Levy D, Labib SB, Anderson KM, Christiansen JC, Kannel WB, Castelli WP (1990) Determinants of sensitivity and specificity of electrocardiographic criteria for left ventricular hypertrophy. Circulation 81(3):815-820. https://doi.org/10.1161/01.cir.81.3. 815

31. Stewart GA, Foster J, Cowan M, Rooney E, McDonagh T, Dargie HJ, Rodger RS, Jardine AG (1999) Echocardiography overestimates left ventricular mass in hemodialysis patients relative to magnetic resonance imaging. Kidney Int 56(6):2248-2253. https://doi.org/10.1046/j.1523-1755.1999.00786.x

32. Drighil A, Madias JE, Yazidi A, Bennani M, Bennis A, Ramdan B, Tahiri A (2008) P-wave and QRS complex measurements in patients undergoing hemodialysis. J Electrocardiol 41(1):60.e6167. https://doi.org/10.1016/j.jelectrocard.2006.03.002

33. Muiesan ML, Salvetti M, Di Castelnuovo A, Paini A, Assanelli D, Costanzo S, Badilini F, Vaglio M, Donati MB, Agabiti Rosei E, de Gaetano G, Iacoviello L (2017) Obesity and ECG left ventricular hypertrophy. J Hypertens 35(1):162-169. https://doi.org/10.1097/ hjh.0000000000001121

34. Hancock EW, Deal BJ, Mirvis DM, Okin P, Kligfield P, Gettes LS, Bailey JJ, Childers R, Gorgels A, Josephson M, Kors JA,
Macfarlane P, Mason JW, Pahlm O, Rautaharju PM, Surawicz B, van Herpen G, Wagner GS, Wellens H (2009) AHA/ACCF/HRS recommendations for the standardization and interpretation of the electrocardiogram: part V: electrocardiogram changes associated with cardiac chamber hypertrophy: a scientific statement from the American Heart Association Electrocardiography and Arrhythmias Committee, Council on Clinical Cardiology; the American College of Cardiology Foundation; and the Heart Rhythm Society. Endorsed by the International Society for Computerized Electrocardiology. J Am Coll Cardiol 53(11):992-1002. https://doi.org/ 10.1016/j.jacc.2008.12.015

35. Agarwal R, Light RP (2011) Determinants and prognostic significance of electrocardiographic left ventricular hypertrophy criteria in chronic kidney disease. Clin J Am Soc Nephrol 6(3):528-536. https://doi.org/10.2215/cjn.07770910

36. Ha LD, Elbadawi A, Froelicher VF (2018) Limited relationship of voltage criteria for electrocardiogram left ventricular hypertrophy to cardiovascular mortality. Am J Med 131(1):101.e101-101.e108. https://doi.org/10.1016/j.amjmed.2017.06.041

37. Mall G, Huther W, Schneider J, Lundin P, Ritz E (1990) Diffuse intermyocardiocytic fibrosis in uraemic patients. Nephrol Dial Transplant 5(1):39-44. https://doi.org/10.1093/ndt/5.1.39

38. London GM, Pannier B, Guerin AP, Blacher J, Marchais SJ, Darne B, Metivier F, Adda H, Safar ME (2001) Alterations of left ventricular hypertrophy in and survival of patients receiving hemodialysis: follow-up of an interventional study. J Am Soc Nephrol 12(12):2759-2767

39. Narayanan K, Reinier K, Teodorescu C, Uy-Evanado A, Chugh H, Gunson K, Jui J, Chugh SS (2014) Electrocardiographic versus echocardiographic left ventricular hypertrophy and sudden cardiac arrest in the community. Heart Rhythm 11(6):1040-1046. https:// doi.org/10.1016/j.hrthm.2014.03.023

40. Charytan D (2014) Is left ventricular hypertrophy a modifiable risk factor in end-stage renal disease. Curr Opin Nephrol Hypertens 23(6):578-585. https://doi.org/10.1097/mnh.0000000000 000067

41. Kovesdy CP, Quarles LD (2013) Fibroblast growth factor-23: what we know, what we don't know, and what we need to know. Nephrol Dial Transplant 28(9):2228-2236. https://doi.org/10.1093/ndt/ gft065

42. Culleton BF, Walsh M, Klarenbach SW, Mortis G, Scott-Douglas N, Quinn RR, Tonelli M, Donnelly S, Friedrich MG, Kumar A, Mahallati H, Hemmelgarn BR, Manns BJ (2007) Effect of frequent nocturnal hemodialysis vs conventional hemodialysis on left ventricular mass and quality of life: a randomized controlled trial. JAMA 298(11):1291-1299. https://doi.org/10.1001/jama.298.11. 1291

43. McCullough PA, Chan CT, Weinhandl ED, Burkart JM, Bakris GL (2016) Intensive hemodialysis, left ventricular hypertrophy, and cardiovascular disease. Am J Kidney Dis 68(5s1):S5-S14. https://doi.org/10.1053/j.ajkd.2016.05.025

44. Yang LY, Ge X, Wang YL, Ma KL, Liu H, Zhang XL, Liu BC (2013) Angiotensin receptor blockers reduce left ventricular hypertrophy in dialysis patients: a meta-analysis. Am J Med Sci 345(1):1-9. https://doi.org/10.1097/MAJ.0b013e318249d387

45. Chertow GM, Levin NW, Beck GJ, Depner TA, Eggers PW, Gassman JJ, Gorodetskaya I, Greene T, James S, Larive B, Lindsay RM, Mehta RL, Miller B, Ornt DB, Rajagopalan S, Rastogi A, Rocco MV, Schiller B, Sergeyeva O, Schulman G, Ting GO, Unruh ML, Star RA, Kliger AS (2010) In-center hemodialysis six times per week versus three times per week. N Engl J Med 363(24):2287-2300. https://doi.org/10.1056/NEJMoa1001593

46. Gong IY, Al-Amro B, Prasad GVR, Connelly PW, Wald RM, Wald R, Deva DP, Leong-Poi H, Nash MM, Yuan W, Gunaratnam L, Kim SJ, Lok CE, Connelly KA, Yan AT (2018) Cardiovascular magnetic resonance left ventricular strain in end-stage renal 
disease patients after kidney transplantation. J Cardiovasc Magn Reson 20(1):83. https://doi.org/10.1186/s12968-018-0504-5

47. Badve SV, Palmer SC, Strippoli GFM, Roberts MA, TeixeiraPinto A, Boudville N, Cass A, Hawley CM, Hiremath SS, Pascoe EM, Perkovic V, Whalley GA, Craig JC, Johnson DW (2016) The validity of left ventricular mass as a surrogate end point for all-cause and cardiovascular mortality outcomes in people with CKD: a systematic review and meta-analysis. Am J Kidney Dis 68(4):554-563. https://doi.org/10.1053/j.ajkd.2016.03.418
Publisher's Note Springer Nature remains neutral with regard to jurisdictional claims in published maps and institutional affiliations. 